\title{
Observational study regarding risk factors and comorbitites for chronic kidney disease in diabetes mellitus patients from Bihor County
}

\author{
Adriana Baidog ${ }^{1,3}$, Cosmin Vesa ${ }^{2,3}$, Ioana Ratiu ${ }^{1,3}$, Monica Sabau ${ }^{2,3}$, Dorina Galusca ${ }^{1,3}$, \\ Gabriel Bako ${ }^{1,3}$, Amorin Popa 2,3 \\ 1"Dr. G. Curteanu” Municipal Clinical Hospital, Oradea, Romania \\ ${ }^{2}$ Clinical County Emergency Hospital of Oradea, Oradea, Romania \\ ${ }^{3}$ University of Oradea, Faculty of Medicine and Pharmacy, Oradea, Romania
}

\begin{abstract}
Introduction. Chronic kidney disease is a common comorbidity in diabetes mellitus type 2 patients because of presence of numerous risk factors such as obesity, hypertension, hyperglycemia and dyslipidemia. Material and methods. Our retrospective, observational study included 300 patients with type 2 diabetes mellitus from Bihor County and had the purpose to establish a clinical profile and to determine the risk factors associated with this pathology. Results. The prevalence of CKD was $75.67 \%$. Older age, worse glucose control, presence of diabetic polyneuropathy and diabetic retinopathy, higher weight, past history of cardiovascular events, the presence of metabolic syndrome and hyperuricemia were associated with the presence of CKD.

Conclusion. The clinical characteristics of type 2 diabetes mellitus patients with CKD is significantly worse compared with the population without CKD.
\end{abstract}

Keywords: diabetes mellitus, chronic kidney disease, risk factors for renal disease

\section{INTRODUCTION}

Diabetes mellitus is a major cause of CKD because of the numerous negative effects of hyperglycemia and insulin resistance at the glomerular level such as increased oxidative stress, glycation of glomerular proteins, activation of pro-inflammatory pathways and osmotic stress (1). Patients with diabetes mellitus are often obsess and have metabolic syndrome. Metabolic syndrome represents a clinical association between obesity, hypertension, hyperglycemia and dyslipidemia that significantly increase the risk of cardiovascular disease, type 2 diabetes, chronic kidney disease (CKD), and total mortality. It was been observed that the incidence of CKD and end-stage renal disease in recent years has paralleled the increasing prevalence of metabolic syndrome has sparked a great interest in the role of metabolic syndrome as a novel risk factor for both cardiovascular disease and CKD (1).

The association between metabolic syndrome and CKD greatly increases the cardiovascular risk, data from one study demonstrated that the presence of CKD (defined as eGFR $<60 \mathrm{ml} / \mathrm{min} / 1.73$ $\mathrm{m} 2$ ) and metabolic syndrome (defined by the NCEP-ATPIII) is associated with a 5.56-fold higher risk of cardiovascular events (2). There are multiple pathways that predispose a person with metabolic syndrome to develop CKD. Hypertension specific for metabolic syndrome increases the intraglomerular pressure with apparition of albuminuria, enhanced sodium reabsorption as an effect of insulin resistance determines the activation or renin-angiotensin-aldosterone system because of lower levels of sodium at the level of macula densa with increased tonus of efferent arteriole and increase of glomerular filtration pressure, dyslipi- 
demia specific in metabolic syndrome promotes inflammation, oxidative stress with podocyte injury and pro-inflammatory cytokine promote the processes of glomerular fibrosis $(3,4)$.

\section{AIM}

The purpose of our retrospective, observational study was to establish the clinical profile, frequency of CKD and to analyze some epidemiological and clinical risk factors for CKD in a cohort of diabetes mellitus patients from Bihor county regardless if they have type 1 or type 2 diabetes mellitus.

\section{MATERIAL AND METHOD}

Our study included 300 patients, with diabetes mellitus type 2 or type 1 , evaluated in one day hospitalization, in the diabetes mellitus ward of the Oradea County Clinical Emergency Hospital. The study was done between 01.01.2016 and 31.12.2018. This study is an observational retrospective one. Systematic sampling method was used for the selection of the patients, every tenth hospitalized patient was included in the study; data used for the research was obtained from the analysis of the medical records. The study was done with the agreement of the hospital's Ethics Committee nr.11379/07.05.2019.

The criteria used for inclusion were: patients with age over 18 years, patients with confirmed diabetes mellitus and complete data in medical record. Exclusion criteria: patients in whom we did not have the complete data needed for the study, patients under medication that may have influenced the results (glucocorticoids), patients with major acute infections (not to influence blood glucose levels).

The following variables were determined for each patient: height, weight, BMI; diabetes mellitus type and duration; presence of comorbidities (cardiovascular disease: hypertension, myocardial infarction, ischemic heart disease), dyslipidemia, hepatic steatosis, presence of micro/macrovascular complications (diabetic retinopathy, diabetic polyneuropathy, arteriopathy). The following biological test values were determined: blood glucose, glycosylated hemoglobin, liver tests, hemoglobin, current and previous creatinine, current and former GFR, uric acid, lipid profile (cholesterol, TGL, HDL, LDL-cholesterol, TGL/HDL-ratio), the presence of proteinuria and/or changes in the urinary sediment.

Metabolic syndrome has been defined according to IDFcriteria (5) as the presence of 3 of the following conditions: systolic blood pressure $\geq 130 \mathrm{mmHg}$ or diastolic blood pressure $\geq 85$ $\mathrm{mmHg}$ or treatment for hypertension, hypertriglyceridemia $\geq 150 \mathrm{mg} / \mathrm{dl}$ or lipid-lowering treatment, increased fasting blood glucose above 100 $\mathrm{mg} / \mathrm{dl}$ or antidiabetic treatment, HDL-cholesterol below $40 \mathrm{mg} / \mathrm{dl}$ in men and below $50 \mathrm{mg} / \mathrm{dl}$ in women or, for those with BMI $>30 \mathrm{~kg} / \mathrm{m}^{2}$ central obesity can be affirmed, even if abdominal circumference was not measured.

Blood pressure values, according to the $\mathrm{ESC} /$ ESH 2018 Guide for the management of hypertension were defined as: normal systolic blood pressure $<130 \mathrm{mmHg}$, diastolic blood pressure $<85$ mmHG, normal-high blood pressure SBP between 130 and $139 \mathrm{mmHg}$, diastolic blood pressure between 85 and $89 \mathrm{mmHg}$, target values for those with hypertension and treatment: below 140/90 $\mathrm{mmHg}(6)$.

Serum uric acid was considered elevated if it had values above $6 \mathrm{mg} / \mathrm{dl}$ in women, respectively $7 \mathrm{mg} / \mathrm{dl}$ in men.In the analysis performed, we included the patients with hyperuricemia who have values above these thresholds but also those who have normal serum uric acid values, but have hyperuricemia treatment (regardless of the type of medication). A value of Hbalc $<7 \%$ was considered as very good glycemic control, a value of Hbalc between 7 and $8 \%$ was considered as good glycemic control, a value of $\mathrm{HbA} 1 \mathrm{c}$ between 8.1 and $9 \%$ was considered as average glucose control while a $\mathrm{HbA} 1 \mathrm{c}>9 \%$ was considered as uncontrolled diabetes mellitus.

CKD was defined according to the guidelines (7) by: reduction of glomerular filtration rate (RFG) below $60 \mathrm{~mL} / \mathrm{min} / 1.73 \mathrm{~m}^{2}$, with a minimum duration of 3 months or renal impairment lasting more than 3 months. Renal impairment can be diagnosed in the absence of knowledge of the etiology and consists of structural or functional abnormalities of the kidney reflected by: anomalies of urine examinations (proteinuria, albuminuria, hematuria, and leukocytosis); abnormalities of blood tests (nitrogen retention, dyselectrolytemia, metabolic acidosis); abnormalities of renal imaging investigations; pathological lesions of the kidneys at renal biopsy.

Statistical analysis was done using the SPSS 26.0 version, values were tested whether they have continuous distribution using KolmogorovSmirnov test. Chi-squared test was used for comparing frequencies and Student test was used for comparing mean values, a value of $p<0.05$ was considered statically significant. 


\section{RESULTS}

The general characteristics of the patients and the incidence of CKD according to stage are illustrated in Table 1 and Table 2.

TABLE 1. Characteristics of the included patients

\begin{tabular}{|c|c|c|}
\hline Parameter & No & $\%$ \\
\hline \multicolumn{3}{|l|}{ Sex } \\
\hline Women & 143 & 47.67 \\
\hline Men & 157 & 52.33 \\
\hline \multicolumn{3}{|l|}{ Age } \\
\hline$<30$ years & 6 & 2 \\
\hline $31-40$ years & 7 & 2.33 \\
\hline $41-50$ years & 25 & 8.33 \\
\hline $51-60$ years & 91 & 30.33 \\
\hline $61-70$ years & 115 & 38.33 \\
\hline$>70$ years & 56 & 18.67 \\
\hline \multicolumn{3}{|l|}{ Living environment } \\
\hline Rural & 98 & 32.67 \\
\hline Urban & 202 & 67.33 \\
\hline \multicolumn{3}{|l|}{ HbA1c } \\
\hline$<7 \%$ & 105 & 35 \\
\hline 7.1-8\% & 59 & 19.67 \\
\hline $8.1-9 \%$ & 55 & 18.33 \\
\hline$>9 \%$ & 81 & 27 \\
\hline \multicolumn{3}{|l|}{ Diabetes complications } \\
\hline With complications & 214 & 71.33 \\
\hline Diabetic polyneuropathy & 200 & 66.67 \\
\hline Diabetic retinopathy & 96 & 32 \\
\hline \multicolumn{3}{|l|}{ Comorbidities } \\
\hline With associated pathology & 287 & 95.67 \\
\hline Cardiovascular disease & 277 & 92.33 \\
\hline Hypertension & 263 & 87.67 \\
\hline Ischemic heart disease & 233 & 77.67 \\
\hline Heart failure & 113 & 37.67 \\
\hline Peripheral artery disease & 80 & 26.67 \\
\hline Hepatic steatosis & 205 & 68.33 \\
\hline COPD & 71 & 23.67 \\
\hline Prostate adenoma & 44 & 14.67 \\
\hline Hypothyroidism & 80 & 26.67 \\
\hline
\end{tabular}

TABLE 2. Prevalence of CKD in the included group

\begin{tabular}{|l|c|c|}
\hline CKD & No & $\%$ \\
\hline CKD & 227 & 75.67 \\
\hline Stage 1 & 16 & 7.05 \\
\hline Stage 2 & 103 & 45.37 \\
\hline Stage 3 & 90 & 39.65 \\
\hline Stage 4 & 17 & 7.49 \\
\hline Stage 5 & 1 & 0.44 \\
\hline
\end{tabular}

The differences between the two groups of diabetes mellitus patients, with and without CKD are illustrated in Table 3 and Table 4.

Both in the group with CKD and in the one without CKD, men predominated $(50.66 \%$ vs $57.53 \%, \mathrm{p}=0.308)$, the ratio men/women being
$1: 1$, respectively $1.4: 1$. In the group with CKD the age of the patients was between 29 and 84 years, and in the group without CKD the age of the patients was between 16 and 83 years. The mean age was 63.84 years in the group with CKD, significantly higher than in the group without CKD (54.93 years, $\mathrm{p}<0.001)$. Both in the group with $\mathrm{CKD}$ and in the one without CKD, the patients from the urban environment predominated (67.84\% vs $65.75 \%, \mathrm{p}=0.741)$, the urban/rural ratio being $2.1: 1$, respectively $1.9: 1$.

In most patients with CKD, the duration of diabetes was over 6 years $(73.57 \%)$, and in those without CKD it was between 1 and 10 years $(65.76 \%)$. The mean duration was significantly longer in patients with CKD than in those without CKD (10.21 years vs. 6.00 years, $p<0.001$ ). Good and very good metabolic control was determined in $50.66 \%$ of patients with CKD and in $67.13 \%$ of those without $\mathrm{CKD}$, the average value of $\mathrm{HbA} 1 \mathrm{c}$ being significantly higher in the group with CKD than in those without CKD $(8.15 \%$ vs. 7.71 , $\mathrm{p}=0.019$ ).

In the group with CKD the prevalence of complications was significantly higher than in the group without CKD (74.45\% vs $61.64 \%, \mathrm{p}=0.036)$. The difference is significant both in the case of polyneuropathy $(70.04 \%$ vs $56.16 \%, \mathrm{p}=0.029)$ and in the case of retinopathy $(36.56 \%$ vs $17.81 \%$, $\mathrm{p}=0.003)$. Oral antidiabetic monotherapy was administered to $35.68 \%$ of patients with CKD, a significantly lower percentage than in patients without CKD $(67.12 \%, p<0.001)$, whereas insulin was administered significantly higher to patients with CKD than in those without $(40.09 \%$ vs $19.18 \%, p=0.001)$.

The combination of oral antidiabetic drug and insulin was significantly lower in patients with CKD than in those without CKD $(24.03 \%$ vs $13.70 \%, p=0.058)$. In patients with $\mathrm{CKD}$, the prevalence of obesity was significantly higher than in patients without CKD (79.30\% vs $57.53 \%$, $\mathrm{p}<0.001$ ), the mean BMI being also significantly higher in patients with CKD $\left(33.27 \mathrm{~kg} / \mathrm{m}^{2}\right.$ vs. $\left.30.93 \mathrm{~kg} / \mathrm{m}^{2}, \mathrm{p}<0.001\right)$. The prevalence of associated diseases was significantly higher in patients with CKD than in those without CKD (98.24\% vs $87.67 \%, \mathrm{p}<0.001)$. With the exception of COPD, prostate adenoma and hypothyroidism, where the prevalence was non significantly higher in patients with CKD $(p>0.05)$, the prevalence of other asso- 
ciated diseases was significantly higher in the group with CKD.

The major cardiovascular events in the antecedents were registered in a significantly higher percentage in the group with CKD $(14.98 \%$ vs $4.11 \%$, $p=0.014)$. Both the prevalence of metabolic syndrome and hyperuricemia was significantly higher in patients with CKD than those without $(81.50 \%$ vs. $67.12 \%, \mathrm{p}=0.010$, respectively $49.78 \%$ vs. $34.25 \%, \mathrm{p}=0.021)$.

TABLE 3. Epidemiological clinical characteristics, comorbidities and pharmacological treatment according to presence or absence of CKD

\begin{tabular}{|c|c|c|c|c|c|}
\hline \multirow[t]{2}{*}{ Parameter } & \multirow{2}{*}{$\begin{array}{c}\text { CKD } \\
(n=227) \\
\text { No. }\end{array}$} & \multirow[b]{2}{*}{$\%$} & \multicolumn{2}{|c|}{$\begin{array}{l}\text { Without CKD } \\
\quad(n=73)\end{array}$} & \multirow[t]{2}{*}{$p$-value } \\
\hline & & & No. & $\%$ & \\
\hline \multicolumn{6}{|l|}{ Sex } \\
\hline Women & 112 & 49.34 & 31 & 42.47 & \multirow{2}{*}{0.30} \\
\hline Men & 115 & 50.66 & 42 & 57.53 & \\
\hline \multicolumn{6}{|l|}{ Age } \\
\hline$<30$ years & 1 & 0.44 & 5 & 6.85 & \multirow{6}{*}{$<0.01$} \\
\hline $31-40$ years & 3 & 1.32 & 4 & 5.48 & \\
\hline $41-50$ years & 15 & 6.61 & 10 & 13.7 & \\
\hline $51-60$ years & 61 & 26.87 & 30 & 41.1 & \\
\hline $61-70$ years & 96 & 42.29 & 19 & 26.03 & \\
\hline$>70$ years & 51 & 22.47 & 5 & 6.85 & \\
\hline \multicolumn{6}{|l|}{ Living environment } \\
\hline Rural & 73 & 32.16 & 25 & 34.25 & \multirow{2}{*}{0.74} \\
\hline Urban & 154 & 67.84 & 48 & 65.75 & \\
\hline \multicolumn{6}{|l|}{ Diabetes duration } \\
\hline$<1$ year & 12 & 5.29 & 11 & 15.07 & \multirow{4}{*}{$<0.01$} \\
\hline $1-5$ years & 48 & 21.15 & 23 & 31.51 & \\
\hline $6-10$ years & 50 & 22.03 & 25 & 34.25 & \\
\hline$>10$ years & 117 & 51.54 & 14 & 19.18 & \\
\hline \multicolumn{6}{|l|}{ HbA1c } \\
\hline$<7 \%$ & 74 & 32.6 & 31 & 42.47 & \multirow{4}{*}{0.01} \\
\hline $7.1-8 \%$ & 41 & 18.06 & 18 & 24.66 & \\
\hline $8.1-9 \%$ & 47 & 20.7 & 8 & 10.96 & \\
\hline$>9 \%$ & 65 & 28.63 & 16 & 21.92 & \\
\hline \multicolumn{6}{|l|}{ Complications } \\
\hline With complications & 169 & 74.45 & 45 & 61.64 & \\
\hline Diabetic polyneuropathy & 159 & 70.04 & 41 & 56.16 & 0.02 \\
\hline Diabetic retinopathy & 83 & 36.56 & 13 & 17.81 & 0.03 \\
\hline \multicolumn{6}{|l|}{ Diabetes treatment } \\
\hline Oral antidiabetics & 81 & 35.68 & 49 & 67.12 & $<0.01$ \\
\hline Insulin & 91 & 40.09 & 14 & 19.18 & $<0.01$ \\
\hline Oral antidiabetics + insulin & 55 & 24.23 & 10 & 13.7 & 0.05 \\
\hline Weight status & & & & & \\
\hline Normal weight & 12 & 5.29 & 9 & 12.33 & \multirow{6}{*}{$<0.01$} \\
\hline Overweight & 35 & 15.42 & 22 & 30.14 & \\
\hline Obesity & 180 & 79.3 & 42 & 57.53 & \\
\hline Obesity gr.1 & 106 & 46.7 & 24 & 32.88 & \\
\hline Obesity gr.2 & 50 & 22.03 & 14 & 19.18 & \\
\hline Obesity gr.3 & 24 & 10.57 & 4 & 5.48 & \\
\hline \multicolumn{6}{|l|}{ Major cardiovascular events } \\
\hline Acute coronary syndrome & 15 & 6.61 & 0 & 0 & \\
\hline Stroke & 15 & 6.61 & 3 & 4.11 & \\
\hline $\begin{array}{l}\text { Acute coronary syndrome + } \\
\text { stroke }\end{array}$ & 4 & 1.76 & 0 & 0 & \multirow[t]{2}{*}{0.01} \\
\hline Total & 34 & 14.98 & 3 & 4.11 & \\
\hline
\end{tabular}


TABLE 4. Prevalence of comorbidities according to CKD presence

\begin{tabular}{|l|c|c|c|c|c|}
\hline \multirow{2}{*}{\multicolumn{1}{|c|}{ Associated diseases }} & \multicolumn{2}{c|}{$\begin{array}{c}\text { CKD } \\
\text { (no=227) }\end{array}$} & \multicolumn{2}{c|}{$\begin{array}{c}\text { Without CKD } \\
\text { (no=73) }\end{array}$} & $p$ \\
\cline { 2 - 6 } & No. & $\%$ & No. & $\%$ & \\
\hline With associated diseases & 223 & 98.24 & 64 & 87.67 & $<0.001$ \\
\hline Cardiovascular disease & 218 & 96.04 & 59 & 80.82 & $<0.001$ \\
\hline Hypertension & 206 & 90.75 & 57 & 78.08 & $<0.001$ \\
\hline Ischemic heart disease & 189 & 83.26 & 44 & 60.27 & $<0.001$ \\
\hline Heart failure & 98 & 43.17 & 15 & 20.55 & $<0.001$ \\
\hline Peripheral artery disease & 67 & 29.52 & 13 & 17.81 & 0.049 \\
\hline Hepatic steatosis & 168 & 74.01 & 37 & 50.68 & $<0.001$ \\
\hline COPD & 56 & 24.67 & 15 & 20.55 & 0.472 \\
\hline Prostate adenoma & 36 & 15.86 & 8 & 10.96 & 0.304 \\
\hline Hypothyroidism & 62 & 27.31 & 18 & 24.66 & 0.657 \\
\hline Metabolic syndrome & 185 & 81.5 & 49 & 67.12 & 0.01 \\
\hline Hyperuricemia & 113 & 49.78 & 25 & 34.25 & 0.02 \\
\hline
\end{tabular}

\section{DISCUSSIONS}

In a study performed on 27,029 type 2 diabetes mellitus patients the factors that were predictors of CKD were age (the prevalence increased with increasing age), sex (male gender was identified as a risk factor), body-mass index (increased bodymass index was associated with increased CKD), triglycerides (increased values associated with increased prevalence) and LDL-cholesterol (8). In our study sex did not have any influence on CKD prevalence, while age and body-mass index were significantly associated with it. Metabolic syndrome as demonstrated by other studies represents an independent predictor of CKD in diabetes mellitus patients (9). The prevalence of cardiovascular disease was significantly higher in our group of CKD patients compared with patients without CKD, as demonstrated by data in literature (10). Patients with retinopathy and polyneuropathy are associated with CKD, as data from literature demonstrates retinopathy is a significant predictor not only for CKD presence but also for CKD progression (11). The same was true for diabetic neuropathy (12), which demonstrated that generally patients with CKD have a significant number of diabetic complications both microvascular and macrovascular. None of the included patients were on SGLT-2 or GLP-1 agonist therapy, this is particularly importance since these drugs decrease cardiovascular risk and offer renal protection, they reduce the risk of a diabetes mellitus patients for glomerular rate filtration decline and progression towards end stage kidney disease (13). It is also significantly that worse glycemic control is associated with $\mathrm{CKD}$, there is no surprise regarding the

Conflict of interest: none declared

Financial support: none declared physio-pathological link between the two but the fact that only $35 \%$ of the included patients have a good glycemic control, a fact confirmed by numerous studies (14). Therapeutical education, use of modern types of insulin, adherence to therapeutic protocols and frequent monitorization of patients are mandatory for improving glucose control (14).

These data illustrate the importance of CKD screening in diabetes mellitus patients that have already at least one microvascular complication. Also, our study demonstrates the importance of interdisciplinary medical evaluation of diabetes mellitus patents with CKD given their higher prevalence of comorbidities, especially the cardiovascular ones.

\section{CONCLUSIONS}

The prevalence of associated diseases was significantly higher in patients with CKD than in those without CKD and the major cardiovascular events in the antecedents were significantly higher in the group with CKD. Both the prevalence of MS and hyperuricemia was significantly higher in patients with CKD than in those without. Given the complex pathology that affects individuals with diabetes mellitus and CKD, physicians should pay attention and not forget about the importance of interdisciplinary in evaluation of these patients. Given the impact of glycemic control and obesity on CKD prevalence, novel therapies such as GLP-1 agonists or SGLT-2 inhibitors can be used as early pharmacologic agents for reducing weight, improving glucose control and offering cardiovascular protection. 


\section{REFERENCES}

1. Maleki A, Montazeri M, Rashidi N, et al. Metabolic syndrome and its components associated with chronic kidney disease. J Res Med Sci. 2015;20(5):465-469.

2. Agrawal S, Shlipak MG, Kramer H, et al. The association of chronic kidney disease and metabolic syndrome with incident cardiovascular events: multiethnic study of atherosclerosis. Cardiol Res Pract. 2012;2012:806102.

3. Lamacchia O, Nicastro V, Camarchio D, et al. Para- and perirenal fat thickness is an independent predictor of chronic kidney disease, increased renal resistance index and hyperuricaemia in type-2 diabetic patients. Nephrol Dial Transplant. 2011;26:892-898.

4. Thomas G, Sehgal AR, Kashyap SR, et al. Metabolic syndrome and kidney disease: a systematic review and meta-analysis. Clin J Am Soc Nephrol. 2011;6:2364-2373.

5. Alberti KG, Zimmet $P$, Shaw J. Metabolic syndrome - a new world-wide definition. A Consensus Statement from the International Diabetes Federation. Diabet Med. 2006 May;23(5):469-80.

6. Williams B, Mancia G, Spiering W, et al. 2018 ESC/ESH Guidelines for the management of arterial hypertension. Eur Heart J. 2018; 39(33):3021-3104.

7. Kidney Disease: Improving Global Outcomes (KDIGO) CKD Work Group. KDIGO 2012 clinical practice guideline for the evaluation and management of chronic kidney disease. Kidney Int Suppl. 2013;3(1):1-150.
8. De Cosmo S, Viazzi F, Pacilli A, et al. Predictors of chronic kidney disease in type 2 diabetes: A longitudinal study from the AMD Annals initiative. Medicine (Baltimore). 2016;95(27):e4007.

9. Shih HM, Chuang SM, Lee CC, Liu SC, Tsai MC. Addition of Metabolic Syndrome to Albuminuria Provides a New Risk Stratification Model for Diabetic Kidney Disease Progression in Elderly Patients. Sci Rep. 2020 Apr 22;10(1):6788.

10. Levin A. Clinical epidemiology of cardiovascular disease in chronic kidney disease prior to dialysis. Semin Dial. 2003;16(2):101-5.

11. Lin HT, Zheng CM, Wu YC, et al. Diabetic Retinopathy as a Risk Factor for Chronic Kidney Disease Progression: A Multicenter Case-Control Study in Taiwan. Nutrients. 2019;11(3):509.

12. Chang HL, Wu CC, Lee SP, et al. A predictive model for progression of CKD. Medicine (Baltimore). 2019 Jun;98(26):e16186.

13. Sarafidis P, Ferro CJ, etal. SGLT-2 inhibitors and GLP-1 receptor agonists for nephroprotection and cardioprotection in patients with diabetes mellitus and chronic kidney disease. A consensus statement by the EURECA-m and the DIABESITY working groups of the ERA-EDTA. Nephrol Dial Transplant. 2019; 34(2):208-230.

14. Selvin E, Parrinello CM, Sacks DB, etal. Trends in prevalence and control of diabetes in the United States, 1988-1994 and 1999-2010. Ann Intern Med. 2014 Apr 15;160(8):517-25. 